\title{
Modifikasi Inisialisasi Cluster head menggunakan Fuzzy C-Means Clustering untuk Efisiensi Energi pada Proses Data Gathering di Lingkungan Wireless Sensor Network
}

\author{
${ }^{1}$ Muhammad Awwib Ahsana, ${ }^{2}$ Waskitho Wibisono \\ ${ }^{1,2}$ Departemen Teknik Informatika, Institut Teknologi Sepuluh Nopember, \\ Indonesia
}

Email: ${ }^{1}$ awwib.18051@mhs.its.ac, ${ }^{2}$ waswib@if.its.ac.id

\section{Tersedia Online di}

http://www.jurnal.unublitar.ac.id/i ndex.php/briliant

\begin{tabular}{l}
\hline Sejarah Artikel \\
\hline Diterima pada 6 Agustus 2020 \\
Disetujui pada 24 November 2020 \\
Dipublikasikan pada 30 November \\
2020 \\
Hal. $839-850$ \\
\hline
\end{tabular}

Kata Kunci:

Data Gathering; LEACH; PSO; WSN

\section{DOI:}

http://dx.doi.org/10.28926/briliant. v3i4.533

transmission dan 7644 round atau $1,6 \mathrm{kali}$ dengan rata-rata energi per transmisi 0.000486052 joule per transmission. Hal in mempertegas bahwa dengan melakukan optimasi data gathering dengan konsep multi hop pada wireless sensor network mampu meningkatkan masa hidup jaringan dan konsumsi energi yang rendah.

\section{PENDAHULUAN}

Jaringan Sensor Nirkabel atau dalam beberapa literature disebut Wireless sensor network (WSN) adalah paradigma yang muncul dari jaringan ad-hoc. Jaringan ini terdiri dari ratusan atau bahkan ribuan sensor node, di mana setiap node akan terhubung satu sama lain. Sensor biasanya saling berkomunikasi dengan node di sekitar atau berinteraksi dengan base station secara langsung untuk mengumpulkan data (Rajagopal, 2018). Istilah ad-hoc merupakan kemampuan perangkat untuk berkomunikasi satu sama lain secara langsung tanpa memerlukan infrastruktur jaringan seperti router atau access point. WSN sendiri mempertimbangkan base station (BS) yang saling berkomunikasi dengan banyak sensor melalui beberapa radio channel. Transmisi data dan proses penerimaan data adalah operasi utama pada WSN (Al-Baz \& El-Sayed, 2018). Routing protokol dalam WSN dibagi dibagi menjadi 3 kategori, yatu location based, data centric, dan hierarchical protocol (Goswami \& Kumar, 2017). 
Pengumpulan data (Data Gathering) merupakan hal yang penting dalam lingkungan WSN, karena hal ini akan berpengaruh terhadap konsumsi energi. Pengumpulan data dilakukan oleh setiap node secara berkala dalam jaringan sensor dan kemudian meneruskan informasi ke sink dengan single hop atau multi hop. Teknik pemngumpulan data dapat dikategorikan menjadi 2 mode, yaitu precision data gathering mode dan correlated data gathering mode (Peng, 2017).

Protokol clustering digunakan untuk pengoptimalan penggunaan energi pada WSN. Sensor dibagi menjadi beberapa area yang dinamakan node dan setiap sensor pada masing-masing area mengirimkan informasi ke Cluster head $(\mathrm{CH})$ dan mentransfer informasi ke Base station (BS) (Nithya, Abhinaya, \& Lavanya, 2018). Communication protocol memiliki peran penting dalam hal efisiensi energi dan peningkatan masa hidup pada WSN. Jadi, sangat penting merancang sebuah protokol pada WSN agar penggunaan energi dapat efisien, karena tidak hanya mengurangi penggunaan energi total jaringan, tetapi juga membuat penggunaan energi menjadi seimbang. Protokol clustering memainkan peran yang sangat penting dalam pengurangan penggunaan energi dalam jaringan. Dalam protokol seperti ini, pemilihan node sebagai $\mathrm{CH}$ sangat penting dalam masa hidup dan penskalaan jaringan.

Salah satu algoritma routing pada WSN yang berbasis clutering adalah Low Energy Adaptive Clustering Hierarchy (LEACH) (W. R. Heinzelman, Chandrakasan, \& Balakrishnan, 2000). LEACH merupakan algoritma yang dapat didistribusikan di mana $\mathrm{CH}$ tidak terikat hanya untuk satu node dan dalam masing-masing periode, setiap node dapat dipilih untuk menjadi $\mathrm{CH}$ secara acak. Mekanisme ini dirancang sedemikian rupa sehingga menjamin peran $\mathrm{CH}$ untuk setiap node. Dalam metode ini, node memposisikan dalam bentuk klaster dan setiap node dapat mengambil tanggung jawab sebagai $\mathrm{CH}$ untuk mengurangi penggunaan energi dan memperpanjang masa hidup jaringan. Versi lain dari LEACH adalah algoritma LEACH-C (W. B. Heinzelman, Chandrakasan, \& Balakrishnan, 2002). Meskipun protokol LEACH dapat memperpanjang masa hidup jaringan, namun disini masih terdapat masalah, di karena pemilihan $\mathrm{CH}$ yang random ini akan berdampak pada distribusi $\mathrm{CH}$ yang kurang optimal. Node dengan energi yang rendah memiliki prioritas yang sama untuk menjadi $\mathrm{CH}$, sama seperti node dengan energi yang tinggi. Oleh karena itu, node-node dengan energi yang lebih sedikit dapat terpilih sebagai $\mathrm{CH}$ yang akan dapat dipastikan node ini akan mati sebelum mencapai ke base station (BS). CH berkomunikasi dengan BS dalam mode single-hop yang membuat LEACH tidak dapat digunakan dalam WSN berskala besar (Xu et al., 2012).

Penelitian (Mehra, Doja, \& Alam, 2018) menggunakan fuzzy untuk menentukan $\mathrm{CH}$ berdasarkan jarak node dengan energi sisa, jarak dari sink, dan kepadatan node di sekitarnya sebagai input ke Fuzzy Inference System. Hasil dari penelitian tersebut menyatakan bahwa dengan menggunakan fuzzy dapat memperpanjang masa pakai jaringan. Penelitian (Alia, 2014), mengusulkan Desentralisation Clustering Fuzzy Protocol atau disebut DCFP, yang meminimalkan pembuangan energi total jaringan untuk meningkatkan masa pakai jaringan. Algoritma fuzzy C-means diadopsi untuk mengalokasikan node sensor ke dalam suatu klaster. Selanjutnya, protokol menjalankan round, di mana setiap round dibagi menjadi 2 fase, yaitu fase $\mathrm{CH}-$ Election dan fase Data Transmission. Dalam fase $\mathrm{CH}$-Election, pemilihan $\mathrm{CH}$ baru dilakukan secara lokal di setiap

840 BRILIANT: Jurnal Riset dan Konseptual Volume 5 Nomor 4, November 2020 
klaster di mana tujuannya untuk meningkatkan kualitas $\mathrm{CH}$ yang terpilih. Pada fase Data Transmission, sensing dan transmisi data dari masing-masing sensor node ke masing-masing $\mathrm{CH}$ dilakukan, dan $\mathrm{CH}$ secara bergantian mengumpulkan dan mengirimkan data sensing ke BS. Hasil simulasi menunjukkan bahwa protokol yang diusulkan meningkatkan masa pakai jaringan, pengiriman data, dan konsumsi energi dibandingkan dengan protokol lainnya.

Penelitian yang dilakukan oleh (Bouyer, Hatamlou, \& Masdari, 2015a) menerangkan bahwa Algoritma Fuzzy C-Means (FCM) digunakan untuk menentukan jumlah $\mathrm{CH}$ yang optimal dan lokasinya. Menggunakan FCM di WSN membantu mengubah parameter protokol LEACH saat eksekusi. Hasilnya menunjukkan bahwa algoritma hybrid meningkatkan masa pakai jaringan dibandingkan dengan algoritma LEACH. Namun pada lingkungan WSN, proses inisialilasi cluster head memiliki permasalahan, yaitu proses inisialisasi cluster head dilakukan secara random. Permasalahan pada proses inisialsisasi secara random terjadi pada saat jumlah node yang sesuai dengan threshold terlalu sedikit dan terlalu banyak yang akan berdampak pada energi yang digunakan oleh node dan sink. Dengan demikian untuk optimasi pada inisialisasi cluster head akan menggunakan metode dari Fuzzy C-Means (FCM) dan Particle Swarm Optimation (PSO).

Dalam penelitian ini, akan berfokus kepada proses modifikasi pada inisialisasi cluster head pada proses data gathering di lingkungan Wireless Sensor Network. Dengan mengimplementasikan metode FCM dan PSO dalam penentuan cluster head, bertujuan untuk mengoptimalkan proses inisialisasi cluster head. metode PSO digunakan untuk menentukan center point selection pada metode FCM, sedangkan proses pada metode FCM digunakan untuk inisialisasi cluster head pada proses data gathering untuk efisiensi energi di lingkungan Wireless Sensor Network.

\section{METODE}

Alur tahapan desain sistem untuk melakukan inisialisasi fuzzy c-means untuk menentukan cluster head pada WSN dapat dilihat pada Gambar 1. Secara keseluruhan, tahapan perancangan desain sistem ini dibagi menjadi 3 proses utama. Proses pertama yaitu fase inisialisasi, proses yang kedua yaitu fase setup, dan yang ketiga yaitu fase steady state. Setiap tahapan akan dibahas secara detail pada Gambar 1.

\section{Fase Inisialisasi}

Fase Inisialisasi merupakan tahapan pertama pada proses ini, dimana dalam fase ini proses inisialisasi awal dalam persebaran node dilakukan secara acak (random). Dalam lingkungan WSN node tersebar secara random dalam suatu area, dalam penelitian ini area yang digunakan 100 x 100 meter, dan setiap node memiliki jumlah energi yang sama. Proses penentuan posisi sink juga akan menjadi hal yang perlu dipertimbangakan, maka dari itu pada fase ini semua parameter seperti biaya transmisi, biaya penerimaan, panjang data, jumlah klaster, jarak node menuju $\mathrm{CH}$, jarak node menuju sink, dan jumlah energi yang dihabiskan akan menjadi perbandingan. 


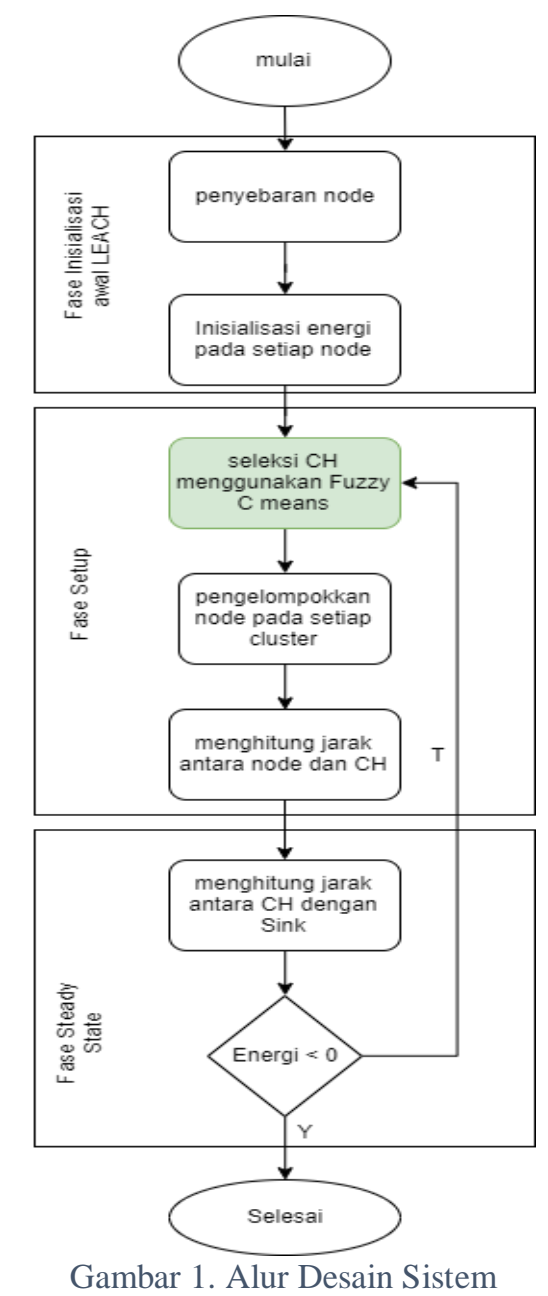

\section{Fase Setup}

Proses pembentukan klaster pada WSN dilakukan pada fase setup. Dalam fase setup dibagi menjadi 3 tahapan, seperti pada Gambar 1 yaitu proses seleksi cluster head, pengelompokan node dengan cluster head, dan menghitung jarak node ke cluster head.

Proses pertama yaitu seleksi cluster head. Dalam penelitian ini, proses seleksi cluster head menggunakan teknik clustering fuzzy c-means dengan mempertimbangkan jarak antar node satu dengan yang lainnya, jumlah cluster, dan sisa energi masing-masing node. Proses penentuan jumlah klaster yang paling optimal berdasarkan penelitian oleh Hoang dkk (Hoang, Kumar, \& Panda, 2010), pada penelitian ini proses menentukan jumlah klaster yang paling optimal dengan menggunakan Persamaan 1.

$c_{\text {opt }}=\frac{\sqrt{N}}{\sqrt{2 * \pi}} \sqrt{\frac{E_{f s}}{E_{m p}}} \frac{M}{d_{t o B S}^{2}}$

Dimana $N$ merupakan jumlah node yang disebar pada suat area secara random, $E_{f s}$ adalah energi yang dibutuhkan untuk mentransmisikan data setiap bit yang digunakan pada mode free space dan $\varepsilon_{m p}$ yang digunakan pada model multipath, $M$ merupakan luas area, sedangkan $d_{\text {toBS }}^{2}$ merupakan jarak rata-rata antara Node ke BS. 


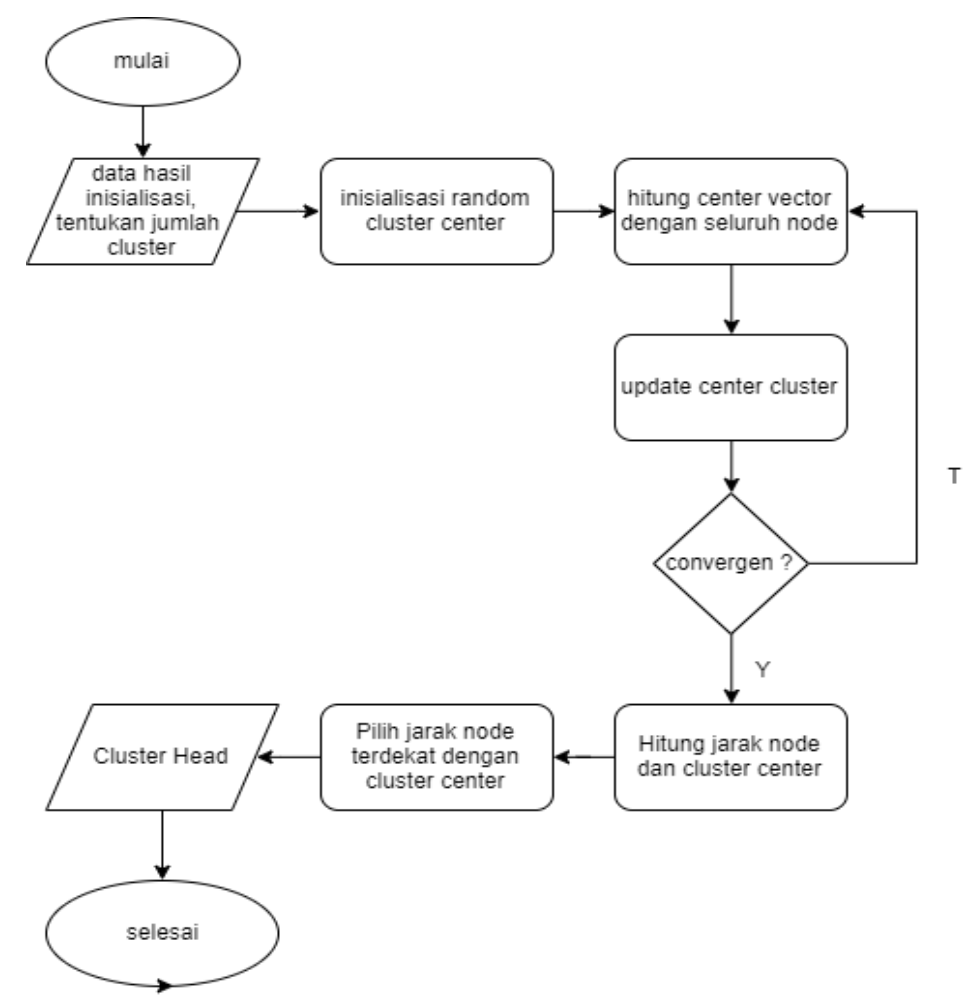

Gambar 2. Alur Proses Inisialisasi Pembentukan Klaster pada WSN

Gambar 2 merupakan alur proses penentuan cluster head dengan menggunakan fuzzy c-means. Jumlah klaster yang akan digunakan pada fuzzy c-means sebanyak jumlah klaster optimal sesuai hasil Persamaan 1. Seperti pada Gambar 2, proses fuzzy c-means dimulai dengan melakukan inisialisasi cluster center sebanyak calon cluster head yang memenuhi persyaratan tersebut. Setelah proses inisialisasi selesai maka dilanjutkan dengan menghitung jarak cluster center fuzzy c-means dengan seluruh node, dengan menggunakan Persamaan 2.

$$
\text { Dicn }=\sqrt{(I C x-N x)^{2}+(I C y-N y)^{2}}
$$

Dimana Dicn adalah jarak inisialisasi klaster dan node ICX adalah posisi inisialisasi klaster pada sumbu $\mathrm{X}, I C y$ adalah posisi inisialisasi klaster pada sumbu Y, $N x$ adalah posisi node A pada sumbu X, dan $N y$ adalah posisi node A pada sumbu Y. Setelah mendapatkan jarak antara cluster center dengan seluruh node, maka akan dipilih node yang memiliki jarak terdekat dan dianggap sebagai klaster baru. Proses pembetukan klaster $(C j)$ menggunakan persamaaan 3. Proses selanjutnya, setelah mendapatkan klaster baru maka akan ditentukan cluster center terbaru dari fuzzy c-means. Proses pembentukan cluster center (IC) menggunkan Persamaan 4. Proses pembentukan cluster baru dan cluster center dilakukan secara berulang-ulang sampai bernilai konvergen. Penentuan nilai konvergen sesuai dengan Persamaan 5.

$C j=\frac{\sum_{i=1}^{n} I C_{(i, j)}^{m} * N}{\sum_{i=1}^{n} I C_{(i, j)}^{m}}$ 


$$
\begin{aligned}
& I C_{(i, j)}=\frac{1}{\sum_{k=1}^{c}\left[\frac{\left\|N_{(i)}-C_{j}\right\|}{\left\|N_{(i)}-C_{k}\right\|}\right]^{\frac{2}{m-1}}} \\
& \text { if }\left\|I C^{(k+1}-I C^{(k)}\right\|<\in \text { than stop }
\end{aligned}
$$

Setelah fuzzy c-means bernilai konvergen maka didapatkan cluster center yang optimal. Proses selanjutnya yaitu menentukan cluster head. Penentuan cluster head dipilih dengan menghitung jarak node dengan cluster center hasil fuzzy cmeans untuk mendapatkan node yang terdekat dari titik cluster center tersebut, dimana titik cluster center terdekat merupakan node yang memiliki jarak paling kecil.

Proses kedua yang dilakukan setelah mendapatkan cluster head yaitu menentukan jumlah cluster pada lingkungan cluster head itu sendiri. Proses pengelompokan node tersebut dengan menghitung jarak terdekat dari setiap cluster head. Proses pembentukan cluster berdasarkan cluster head menggunakan persamaan 6. Proses ketiga setelah mendapatkan cluster dari cluster head yaitu menghitung jarak node menuju setiap cluster headnya masing-masing. Proses perhitungan jarak node menuju setiap cluster head menggunakan Persamaan 7.

$$
\begin{aligned}
C_{\text {new }} & =\frac{\sum_{i=1}^{n} C H_{(i, j)}^{m} * N}{\sum_{i=1}^{n} C H_{(i, j)}^{m}} \\
D c h & =\sqrt{\left(C H x-N C_{\text {new }}\right)^{2}+\left(C H y-N C_{\text {new }}\right)^{2}}
\end{aligned}
$$

Dimana $C_{\text {new }}$ adalah cluster baru berdasarkan custer head, Dch adalah jarak cluster head terhadap node pada $C_{\text {new }}, N C_{\text {new }}$ adalah node pada $C_{\text {new }}, C H x$ adalah Cluster head pada sumbu X, dan CHy adalah cluster head pada sumbu Y.

Setelah proses penentuan cluster head pada setiap cluster, maka proses selanjutnya dilakukan pencarian cluster head utama yang akan melakukan transmisi dengan Sink. Proses penentuan cluster utama dengan menggunakan Particle Swarm Optimization (PSO). Langkah-langkah PSO yaitu:

Langkah 1: Melakukan inisialisasi pada kumpulan partikel, termasuk ukuran populasi, posisi awal dan kecepatan partikel.

Langkah 2: Menghitung fitness untuk setiap partikel, simpan setiap posisi terbaik partikel $P_{-}$best dan fitness, dan pilih partikel yang memiliki fitness terbaik sebagai G_best.

Langkah 3: Perbarui kecepatan dan posisi masing-masing partikel sesuai dengan Persamaan 8 dan 9.

$$
\begin{aligned}
& V_{i}^{n+1}=V_{i}^{n}+c_{1} r_{1}\left(P_{i}-X_{i}^{n}\right)+c_{2} r_{2}\left(P_{g}-X_{i}^{n}\right) \\
& V_{i}^{n+1}=X_{i}^{n}+V_{i}^{n}
\end{aligned}
$$

Langkah 4: Menghitung fitness pada setiap partikel setelah posisi diperbarui, lalu bandingkan fitness pada setiap partikel dengan fitness terbaik sebelumnya P_best, jika lebih baik, maka atur posisi saat ini sebagai P_best. 
Langkah 5: Bandingkan fitness pada setiap partikel dengan kelompok fitness terbaik sebelumnya, jika lebih baik dari itu, maka atur posisi saat ini sebagai G_best.

Langkah 6: Cari algoritma untuk menentukan apakah hasilnya memenuhi persyaratan yang ditetapkan pada akhir, jika persyaratan tidak terpenuhi, maka kembali ke Langkah 3, jika perasyarat terpenuhi, maka iterasi dihentikan sehingga dihasilkan output partikel optimal.

\section{Fase Steady State}

Fase steady state merupakan fase untuk melakukan transmisi atau pengiriman paket data ke $\mathrm{CH}$ dan sink, selain itu pada fase ini juga untuk melakukan perhitungan biaya transmisi dan biaya penerimaan oleh sink. Pada fase ini jarak masing-masing node yang menuju cluster head dihitung menggunakan rumus Euclidian Distance antara node $\mathrm{A}(\mathrm{x}, \mathrm{y})$ dan node $\mathrm{CH}(\mathrm{x}, \mathrm{y})$. Dapat dihitung dengan Persamaan 9.

Dtch $=\sqrt{\left(\mathrm{A}_{\mathrm{x}}-\mathrm{CH}_{\mathrm{x}}\right)^{2}+\left(\mathrm{A}_{\mathrm{y}}-\mathrm{CH}_{\mathrm{y}}\right)^{2}}$

Dimana Dtch adalah jarak node menuju $\mathrm{CH}, \mathrm{A}_{\mathrm{x}}$ adalah posisi node $\mathrm{A}$ pada sumbu $\mathrm{X}, \mathrm{A}_{\mathrm{y}}$ adalah posisi node $\mathrm{A}$ pada sumbu $\mathrm{Y}, \mathrm{CH}_{\mathrm{x}}$ adalah posisi $\mathrm{CH}$ pada sumbu X, dan $\mathrm{CH}_{\mathrm{y}}$ adalah posisi $\mathrm{CH}$ pada sumbu $\mathrm{Y}$.

Proses selanjutnya, setiap node dalam cluster melakukan pengiriman data dari anggota node menuju cluster head. Cluster head bertanggung jawab untuk mengirimkan data kepada sink. Proses pengiriman data oleh cluster head dihitung berdasarkan jarak dari cluster head menuju sink dengan menggunkan euclidian distance antara cluster head (x,y) dan sink (x,y). Persamaan 10 merupakan euclidian distance untuk cluster head terhadap sink.

Dts $=\sqrt{\left(A_{x}-\operatorname{SinkX}\right)^{2}+\left(A_{y}-\operatorname{SinkY}\right)^{2}}$

Dengan Dts merupakan jarak node menujus sink, $A_{x}$ merupakan posisi node $A$ pada sumbu $X, A_{y}$ merupakan posisi node A pada sumbu $Y$, SinkX merupakan posisi sink pada sumbu X, dan SinkY merupakan posisi sink pada sumbu Y.

\section{Model Jaringan}

Dalam penelitian ini digunakan beberapa asumsi dalam model jaringan WSN. Adapun asumsi model jaringan WSN yang digunakan adalah Sensor node dengan base statition berada dalam kondisi standby setelah disebar didalam area. Jaringan bersifat homogen dan semua sensor node memiliki jumlah energi yang sama. Setiap sensor node mengetahui posisi koordinat node tetangga. Semua node dapat menghitung paramater yang telah ditentukan pada area tersebut dan mengirim secara berkala kepada node penerima. Sinyal radio mempunyai energi yang sama seperti saat mengirimkan data transmisi dari node $\mathrm{A}$ ke node $\mathrm{B}$, sama halnya proses pengiriman data dari node $\mathrm{B}$ menuju node A. setiap sensor dapat beroperasi dalam sensing mode untuk memantau parameter pada area tersebut dan 
mengirimkan cluster head untuk mengumpulkan data dan meneruskan pengiriman data kepada base station. Sink bersifat statis

\section{Radio Energi Model}

Radio dan model energi yang digunakan pada penelitian ini pada setiap transmisinya akan dihitung menggunakan persamaan yang sama dengan Heinzelman dkk (W. R. Heinzelman et al., 2000). Menurut jarak antara transmitter dan receiver, konsumsi energi akan diukur dengan dissipation model radio. Dan sesuai dengan jarak dari target, free space dan multi-path fading model dapat digunakan. Konsumsi energi dari node pengirim termasuk konsumsi energi dari sirkuit pengirim dan penguatan daya. Oleh karena itu, untuk mengirimkan pesan $k$ bit pada jarak $d$, konsumsi energi dapat dirumuskan pada Persamaan 11.

$E_{t x}(k, d)=E_{T x-e l e c}(k)+T_{T x-a m p}(k, d)=\left\{\begin{array}{c}E_{\text {elec }} * k+\varepsilon_{f s} * k * d^{2}, d \leq d_{0} \\ E_{\text {elec }} * k+\varepsilon_{m p} * d^{4}, d>d_{0}\end{array}\right.$

Dimana $E_{T x-e l e c}, T_{T x \text {-amp }}$ adalah konsumsi energi dengan menerima dan mengirimkan pesan dari setiap node. $\varepsilon_{f s}, \varepsilon_{m p}$ adalah konsumsi daya free space propagation dan konsumsi daya multipath propagation. $E_{\text {elec }}$ adalah energi/bit yang dikonsumsi oleh pemancar atau penerima elektronik. $d_{0}$ adalah nilai treshold. Jika jarak transmisi kurang dari ambang batas $d_{0}$, maka free space model diterapkan, namun jika tidak kami menggunakan model multipath. Nilai threshold $d_{o}$ dapat dihitung menggunakan Persamaan 12.

$d_{o}=\sqrt{E_{f s} / E_{m p}}$

Sedangkan pada perangkat penerima, untuk menghitung k-bit packet data unit yang diterima pada saat digunakan dapat menggunakan rumus pada Persamaan 13.

$E_{R x}(k)=E_{R x-e l e c}(k)=E_{\text {elec }} * k$

Dimana $E_{R x}(k)$ merupakan energi yang dibutuhkan oleh penerima untuk menerima sejumlah bit packet data unit setiap data $k$-bit. Sedangkan $E_{\text {elec }}$ merupakan energi yang dihabiskan untuk mengoperasikan sirkuit transceiver

\section{HASIL}

Inisiasi Pada bagian ini dilakukan simulasi WSN dengan menggunakan bahasa pemrograman MATLAB. Simulasi ini membandingkan protokol clustering untuk data gathering yaitu Low Energy Adaptive Clustering Hierarchy (LEACH) dengan usulan fuzzy c-means yang telah dioptimasi. Parameter yang dibandingkan yaitu network lifetime dan energy consumption per transmition. Seperti yang telah dilakukan pada penelitian sebelumnya oleh Asgarali Bouyer dkk (Bouyer, Hatamlou, \& Masdari, 2015b), sebagai acuan, parameter uji coba dapat dilihat pada Tabel 1. 
Tabel 1. Parameter Uji Coba

\begin{tabular}{l|l}
\hline Parameter & Nilai \\
\hline Area Simulasi & $100 * 100 \mathrm{~m}$ \\
Jumlah node & 100 \\
Initial Energy $\left(E_{\text {init }}\right)$ & $0,5 \mathrm{~J}$ \\
Electronic circuit & $50 \mathrm{~nJ} / \mathrm{bit}$ \\
energy $\left(E_{\text {elec }}\right)$ & \\
Sink & $50 * 100$ \\
\hline
\end{tabular}

Hasil pentuan jumlah cluster optimal berdasarkan Persamaan 1 mendapatkan 8 klaster. Jumlah klaster tersebut sebagai inisialisasi pada proses Fuzzy C-means. Gambar 3 merupakan hasil proses Fuzzy C-means. Setiap klaster hasil fuzzy cmeans memiliki cluster head masing-masing. Cluster head pada setiap klaster ditunjukan dengan simbol X (merah), sedangkan cluster head utama hasil dari proses Particle Swarm Optimization ditunjukan oleh simbol + (hitam). Jumlah klaster dan hasil klaster dari fuzzy c-means tidak mengalami perubahan, tetapi cluster head pada setiap klaster dan cluster head utama dilakukan perubahan pada setiap roundnya.

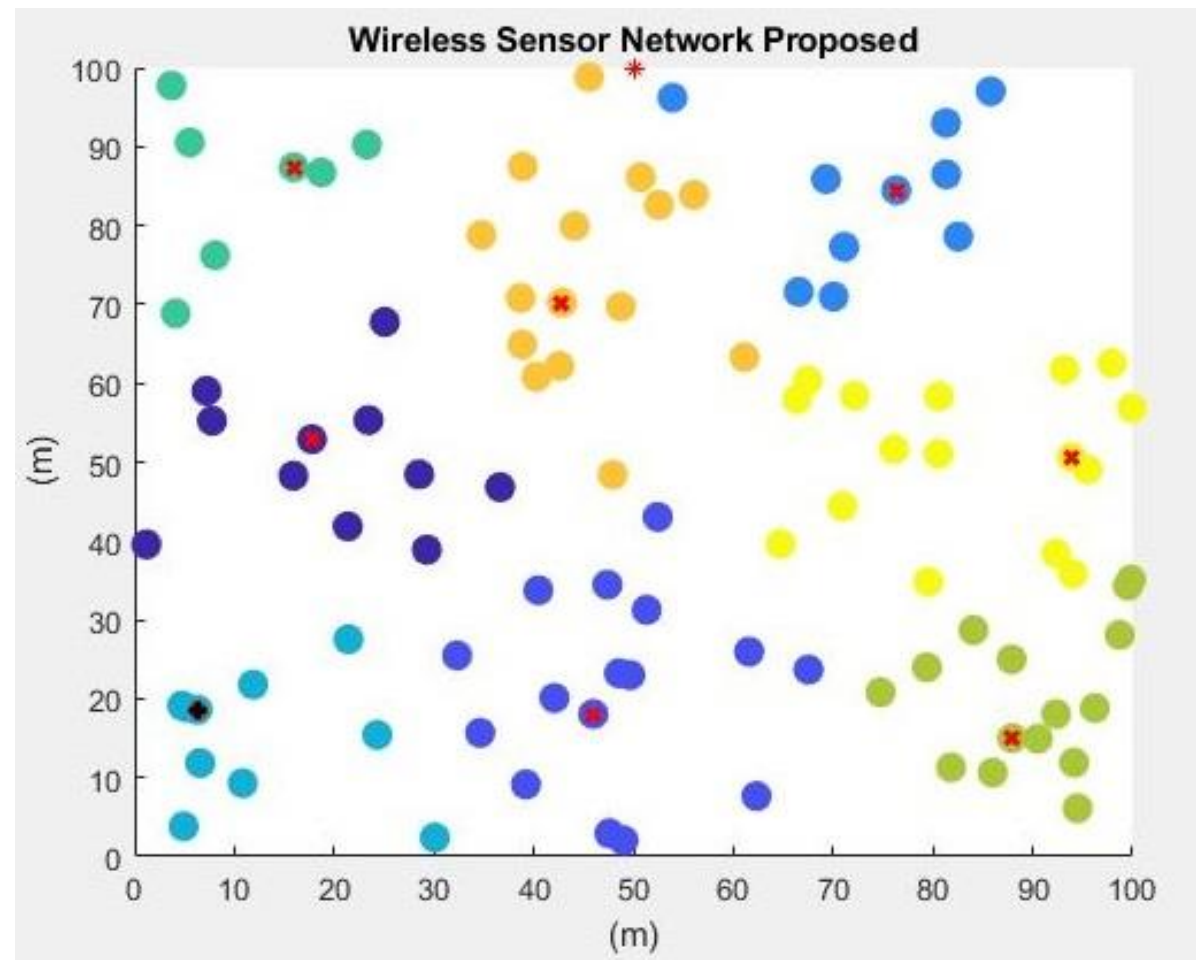

Gambar 3. Hasil proses Fuzzy C-means

\section{Hasil perbandingan Network Lifetime}

Berdasarkan hasil uji coba protocol LEACH dan protokol usulan, protokol yang disusulkan memiliki network lifetime yang lebih panjang dari pada protokol LEACH. Hasil uji coba menunjukkan bahwa protokol usulan mempunyai masa hidup jaringan mencapai 7441 round, sedangkan masa hidup jaringan pada LEACH hanya mencapai 5319 round. Hasil simulasi perbandingan protokol LEACH dan protokol usulan dapat dilihat pada Gambar 4. 


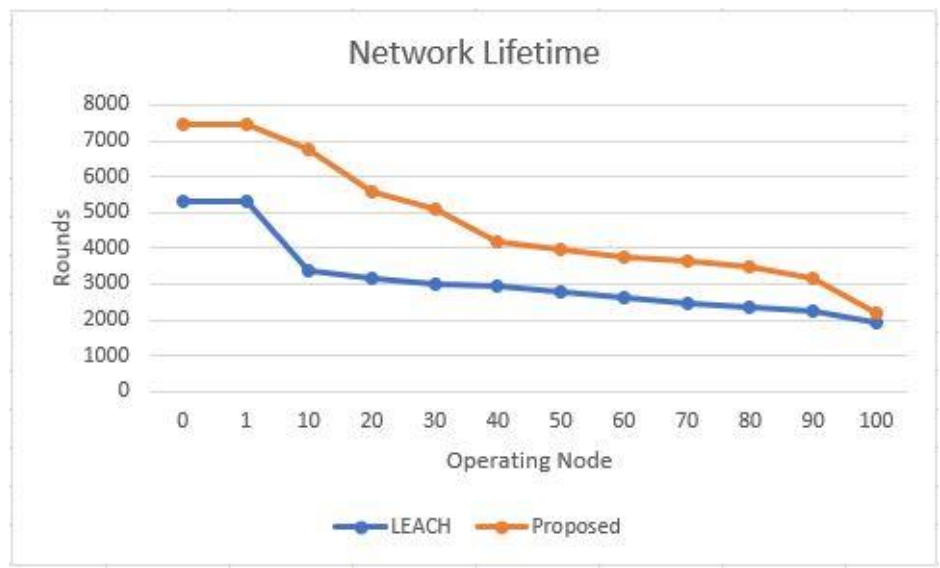

Gambar 4. Network Lifetime

\section{Hasil perbandingan Consumption Energy per Transmition.}

Consumption Energy per Transmition merupakan energi yang dipakai semua node dalam setiap transmisi, baik dari node $\mathrm{ke} \mathrm{CH}$ maupun dari $\mathrm{CH}$ ke sink. Hasil simulasi menunjukkan bahwa protokol usulan mempunyai konsumsi energi yang lebih sedikit dari pada protokol LEACH yaitu sebesar 0.044705 joule per transmission untuk protocol usulan sedangan pada protocol LEACH energi yang dipakai sebesar 0.075186 joule per transmission. Hasil pengujian ditunjukkan pada Gambar 4.

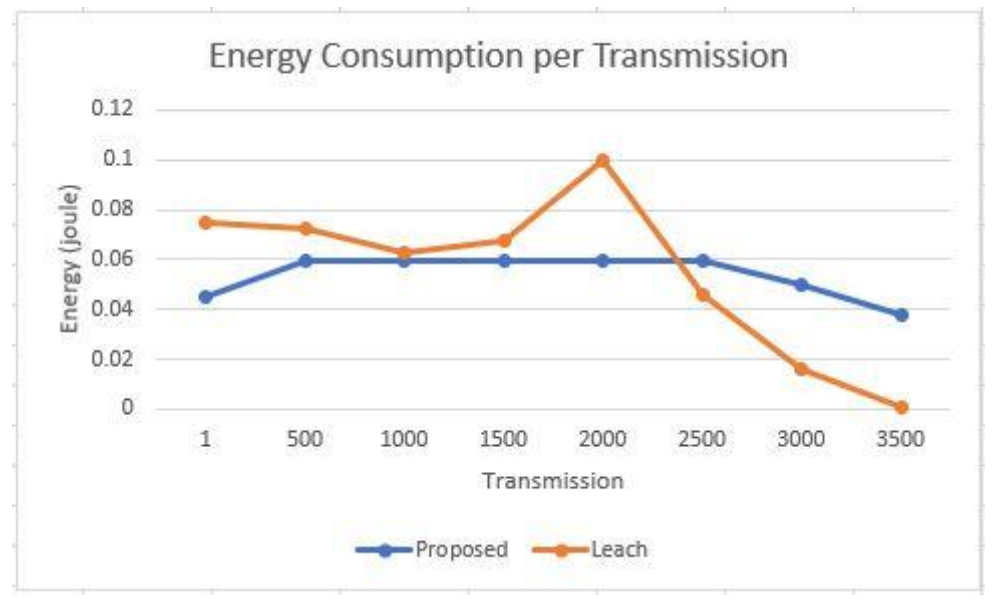

Gambar 4. Energy Consumption per Transmission

\section{PEMBAHASAN}

Penentuan jumlah klaster mendapatkan klaster optimal seperti pada pembahasan hasil memiliki pengaruh bahwa jika jumlah klaster terlalu sedikit atau terlalu banyak, maka mengurangi kinerja dari network lifetime dan meningkatkan jumlah konsumsi energi yang digunakan. Hal ini bisa mengakibatkan pengurangan kemampuan dari wireless sensor network.

Berdasarkan hasil uji coba protokol LEACH dan protokol usulan, protokol yang disusulkan memiliki network lifetime yang lebih panjang dari pada protokol LEACH. Hasil uji coba menunjukkan bahwa protokol usulan mempunyai masa hidup jaringan mencapai 9549 round pada posisi sink 50,50 dan mencapai 7644 round pada posisi sink 50,100. Sedangkan masa hidup jaringan pada LEACH 
hanya mencapai 4628 round pada posisi sink 50,50 dan mencapai 4671 round pada posisi sink 50,100. Hasil simulasi perbandingan protokol LEACH dan protokol usulan terkait network lifetime

Consumption Energy per Transmition merupakan energi yang dipakai semua node dalam setiap transmisi, baik dari node ke $\mathrm{CH}, \mathrm{CH}$ ke $\mathrm{CH}$ utama, $\mathrm{CH}$ ke sink, dan $\mathrm{CH}$ utama ke sink. Hasil simulasi menunjukkan bahwa protokol usulan mempunyai konsumsi energi yang lebih sedikit dari pada protokol LEACH. Hasil transmisi pertama menunjukkan bahwa konsumsi energi setiap transmisi untuk LEACH pada sink $(50,50)$ yaitu 0,083480212 joule per transmission, LEACH pada sink $(50,100) 0,059269898$ joule per transmission, proposed pada sink $(50,50)$ 0,046132937 joule per transmission, dan proposed pada sink (50,100) 0,043135609 joule per transmission. Hasil simulasi perbandingan protokol LEACH dan protokol usulan terkait consumption energy per transmition.

\section{KESIMPULAN}

Dalam penelitian ini, berfokus kepada proses modifikasi pada inisialisasi cluster head pada proses data gathering di lingkungan Wireless Sensor Network. Dengan mengimplementasikan metode FCM dan PSO dalam penentuan cluster head. metode PSO digunakan untuk menentukan cluster head utama, sedangkan proses pada metode FCM digunakan untuk inisialisasi cluster head pada proses data gathering untuk efisiensi energi di lingkungan Wireless Sensor Network.

Hasil uji coba menunjukkan bahwa protokol usulan mempunyai masa hidup jaringan mencapai 7441 round, sedangkan masa hidup jaringan pada LEACH hanya mencapai 5319 round, sedangkan dalam hal konsumsi energi protokol usulan mempunyai konsumsi energi yang lebih sedikit dari pada protokol LEACH yaitu sebesar 0.044705 joule per transmission untuk protokol usulan sedangan pada protocol LEACH energi yang dipakai sebesar 0.075186 joule per transmission. Berdasrkan pengujian yang telah dilakukan, protokol usulan memiliki masa hidup jaringan lebih panjang dan konsumsi energi lebih rendah dibandingan protokol LEACH.

\section{SARAN}

Dari penelitian yang telah dilakukan masih terdapat hal yang dapat dikembangkan seperti tidak hanya mempertimbangkan kepadatan jarak antar node ataupun jarak antar cluster head namun dapat menambahkan variabel yang lain agar konsumsi energi yang digunakan dapat lebih hemat dan network lifetime bisa lebih optimal.

\section{DAFTAR RUJUKAN}

Al-Baz, A., \& El-Sayed, A. (2018). A new algorithm for cluster head selection in LEACH protocol for wireless sensor networks. International Journal of Communication Systems, 31(1), 1-13. https://doi.org/10.1002/dac.3407

Alia, O. M. D. (2014). A decentralized fuzzy c-means-based energy-efficient routing protocol for wireless sensor networks. Scientific World Journal, 2014. https://doi.org/10.1155/2014/647281

Bouyer, A., Hatamlou, A., \& Masdari, M. (2015a). A new approach for decreasing energy in wireless sensor networks with hybrid LEACH protocol 
and fuzzy C-means algorithm. International Journal of Communication Networks and Distributed Systems, 14(4), 400-412. https://doi.org/10.1504/IJCNDS.2015.069675

Bouyer, A., Hatamlou, A., \& Masdari, M. (2015b). A new approach for decreasing energy in wireless sensor networks with hybrid LEACH protocol and fuzzy C-means algorithm. International Journal of Communication Networks and Distributed Systems, 14(4), 400-412. https://doi.org/10.1504/IJCNDS.2015.069675

Goswami, A., \& Kumar, M. (2017). A Review on Energy Harvesting in Wireless. https://doi.org/10.15680/IJIRSET.2017.0604138

Heinzelman, W. B., Chandrakasan, A. P., \& Balakrishnan, H. (2002). An application-specific protocol architecture for wireless microsensor networks. IEEE Transactions on Wireless Communications, 1(4), 660-670. https://doi.org/10.1109/TWC.2002.804190

Heinzelman, W. R., Chandrakasan, A., \& Balakrishnan, H. (2000). Energyefficient communication protocol for wireless microsensor networks. Proceedings of the Hawaii International Conference on System Sciences. https://doi.org/10.1109/hicss.2000.926982

Hoang, D. C., Kumar, R., \& Panda, S. K. (2010). Fuzzy C-means clustering protocol for Wireless Sensor Networks. IEEE International Symposium on Industrial Electronics, 3477-3482. https://doi.org/10.1109/ISIE.2010.5637779

Mehra, P. S., Doja, M. N., \& Alam, B. (2018). Fuzzy based enhanced cluster head selection (FBECS) for WSN. Journal of King Saud University - Science. https://doi.org/10.1016/j.jksus.2018.04.031

Nithya, B., Abhinaya, S. B., \& Lavanya, V. (2018). A Party-based Cluster Head Selection Algorithm for Wireless Sensor Networks. 2018 International Conference on Computing, Power and Communication Technologies (GUCON), 327-332. https://doi.org/10.1109/GUCON.2018.8675041

Peng, K. (2017). A Survey of Energy-efficient Data Gathering of Wireless Sensor Networks. Journal of Software Engineering, 11(1), 94-101. https://doi.org/10.3923/jse.2017.94.101

Rajagopal, A. (2018). Performance Analysis for Efficient Cluster Head Selection in Wireless Sensor Network Using RBFO and Hybrid BFO-BSO. International Journal of Wireless Communications and Mobile Computing, 6(1), 1. https://doi.org/10.11648/j.wcmc.20180601.11

Xu, J., Jin, N., Lou, X., Peng, T., Zhou, Q., \& Chen, Y. (2012). Improvement of LEACH protocol for WSN. 2012 9th International Conference on Fuzzy Systems and Knowledge Discovery, (Fskd), 2174-2177. https://doi.org/10.1109/FSKD.2012.6233907 